\title{
Asymmetric and Selective Biocatalysis
}

\author{
Cesar Mateo * (D) and Jose M. Palomo *(D) \\ Department of Biocatalysis, Institute of Catalysis (ICP-CSIC), Marie Curie 2, Cantoblanco, Campus UAM, \\ 28049 Madrid, Spain \\ * Correspondence: ce.mateo@icp.csic.es (C.M.); josempalomo@icp.csic.es (J.M.P.); \\ Tel.: +34-915-854-768 (C.M. \& J.M.P.)
}

Received: 14 November 2018; Accepted: 15 November 2018; Published: 28 November 2018

The synthesis of compounds or chiral building-blocks with the desired configuration is one of the greatest challenges of chemistry and is of great interest in different fields such as analytical chemistry and especially in fine and pharmaceutical chemistry. Different biocatalysts (cells, enzymes, catalytic antibodies, or ribozymes) have been used to catalyze different processes, even on an industrial scale. Biocatalysts have high activity under very mild conditions such as ambient temperature, neutral $\mathrm{pH}$, and atmospheric pressure. They are also able to catalyze highly selective and specific modifications in different substrates with high complexity, allowing the synthesis of enantiomerically pure compounds either by resolution processes or by asymmetric synthesis from prochiral substrates or regioselective modifications in complex molecules. This avoids side reactions as well as costly purification processes.

In recent years, in addition to the pure biocatalysts traditionally used, different hybrid catalysts have been developed, which combine the good catalytic properties of traditional biocatalysts with the properties of organometallic catalysts. In this way, different mixed catalysts have been developed as artificial metalloenzymes combining enzymatic and metallic catalytic activities, expanding the applicability to different systems such as cascade processes.

This issue contains one communication, six articles, and two reviews.

The communication from Paola Vitale et al. [1] represents a work where whole-cells were used as biocatalysts for the reduction of optically active chloroalkyl arylketones, followed by a chemical cyclization to give the desired heterocycles. Among the various whole cells screened (baker's yeast, Kluyveromyces marxianus CBS 6556, Saccharomyces cerevisiae CBS 7336, Lactobacillus reuteri DSM 20016), baker's yeast provided the best yields and the highest enantiomeric ratios (95:5) in the bioreduction of the above ketones. In this respect, valuable, chiral non-racemic functionalized oxygen-containing heterocycles (e.g., (S)-styrene oxide, (S)-2-phenyloxetane, (S)-2-phenyltetrahydrofuran), amenable to be further elaborated on, can be smoothly and successfully generated from their prochiral precursors.

Research regarding pure biocatalysts utilizing mechanistic studies, their application in different reactions and new immobilization methods for improving stability featured in five different articles.

The article by Su-Yan Wang et al. [2] describes the cloning, expression, purification, and characterization of an $\mathrm{N}$-acetylglucosamine 2-epimerase from Pedobacter heparinus ( $\mathrm{PhGn} 2 \mathrm{E}$ ). For this research, several $\mathrm{N}$-acylated glucosamine derivatives were chemically synthesized and used to test the substrate specificity of the enzyme. The mechanism of the enzyme was studied by hydrogen/deuterium NMR. The study of the anomeric hydroxyl group and C-2 position of the substrate in the reaction mixture confirmed the epimerization reaction via ring-opening/enolate formation. Site-directed mutagenesis was also used to confirm the proposed mechanism of this interesting enzyme.

The article by Forest $\mathrm{H}$. Andrews et al. [3] studies two enzymes benzoylformate decarboxylase (BFDC) and pyruvate decarboxylase (PDC) that catalyze the non-oxidative decarboxylation of 2-keto acids with different specificity. BFDC from P. putida exhibited very limited activity with pyruvate, 
whereas the PDCs from S. cerevisiae or from Z. mobilis showed virtually no activity with benzoylformate (phenylglyoxylate). After research using saturation, mutagenesis BFDC T377L/A460Y variant was obtained, with a 10,000-fold increase in pyruvate/benzoylformate. The change was attributed to an improvement in the $K m$ value for pyruvate and a decrease in the $k_{\text {cat }}$ value for benzoylformate. The characterization of the new catalyst was performed providing context for the observed changes in the specificity.

The article by Xin Wang et al. [4] compares two types of biocatalysts to produce D-lysine L-lysine in a cascade process catalyzed by two enzymes: racemase from microorganisms that racemize L-lysine to give D,L-lysine and decarboxylase that can be in cells, permeabilized cells, and the isolated enzyme. The comparison between the different forms demonstrated that the isolated enzyme showed greater decarboxylase activity. Under optimal conditions, $750.7 \mathrm{mmol} / \mathrm{L}$ D-lysine was finally obtained from $1710 \mathrm{mmol} / \mathrm{L} \mathrm{L}-\mathrm{lysine}$ after $1 \mathrm{~h}$ of racemization reaction and $0.5 \mathrm{~h}$ of decarboxylation reaction. D-lysine yield could reach $48.8 \%$ with enantiomeric excess (ee) of $99 \%$.

In the article of Rivero and Palomo [5], lipase from Candida rugosa (CRL) was highly stabilized at alkaline $\mathrm{pH}$ in the presence of $\mathrm{PEG}$, which permits its immobilization for the first time by multipoint covalent attachment on different aldehyde-activated matrices. Different covalent immobilized preparation of the enzyme was successfully obtained. The thermal and solvent stability was highly increased by this treatment and the novel catalysts showed high regioselectivity in the deprotection of per-O-acetylated nucleosides.

The article by Robson Carlos Alnoch et al. [6] describes the protocol and use of a new generation of tailor-made bifunctional supports activated with alkyl groups that allow the immobilization of proteins through the most hydrophobic region of the protein surface and aldehyde groups that allow the covalent immobilization of the previously adsorbed proteins. These supports were especially used in the case of lipase immobilization. The immobilization of a new metagenomic lipase (LipC12) yielded a biocatalyst 3.5-fold more active and 5000-fold more stable than the soluble enzyme. The PEGylated immobilized lipase showed high regioselectivity, producing high yields of the C-3 monodeacetylated product at $\mathrm{pH} 5.0$ and $4{ }^{\circ} \mathrm{C}$.

The hybrid catalysts composed by an enzyme and metallic complex is also covered in this Special Issue.

The article by Christian Herrero et al. [7] describes the development of the $\mathrm{Mn}(\mathrm{TpCPP})-\mathrm{X} \ln 10$ A artificial metalloenzyme, obtained by non-covalent insertion of $\mathrm{Mn}$ (III)-meso-tetrakis(pcarboxyphenyl)porphyrin [Mn(TpCPP), 1-Mn] into xylanase 10 A from Streptomyces lividans (Xln10 A). The complex was found to be able to catalyze the selective photo-induced oxidation of organic substrates in the presence of $\left[\mathrm{RuII}(\mathrm{bpy})_{3}\right]^{2+}$ as a photosensitizer and $\left[\mathrm{CoIII}\left(\mathrm{NH}_{3}\right)_{5} \mathrm{Cl}\right]^{2+}$ as a sacrificial electron acceptor, using water as an oxygen atom source.

The two published reviews describe different subjects of interest to the fields of biocatalysis and mix metallic-biocatalysis respectively.

The review by Anika Scholtissek et al. [8] describes the state-of-the-art of ene-reductases from the old yellow enzyme family (OYEs) to catalyze the asymmetric hydrogenation of activated alkenes to produce chiral products with industrial interest. The dependence of OYEs on pyridine nucleotide coenzyme can be avoided by using nicotinamide coenzyme mimetics. In the review, three main types of OYEs classification are described and characterized.

The review by Yajie Wang and Huimin Zhao [9] highlights some of the recent examples in the past three years that combined transition metal catalysis with enzymatic catalysis. With recent advances in protein engineering, catalyst synthesis, artificial metalloenzymes, and supramolecular assembly, there is great potential to develop more sophisticated tandem chemoenzymatic processes for the synthesis of structurally complex chemicals.

In conclusion, these nine publications give an overview of the possibilities of different catalysts, both traditional biocatalysts and hybrids with metals or organometallic complexes, to be used in different processes, in particular in synthetic reactions at very mild reaction conditions. 
Author Contributions: Both authors contributed in writing the manuscript.

Funding: This work was supported by the Spanish Government (AGL2017-84614-C2-1-R and AGL201784614-C2-2-R).

Conflicts of Interest: The authors declare no conflict of interest.

\section{References}

1. Vitale, P.; Digeo, A.; Perna, F.M.; Agrimi, G.; Salomone, A.; Scilimati, A.; Cosimo Cardellicchio, C.; Capriati, V. Stereoselective Chemoenzymatic Synthesis of Optically Active Aryl-Substituted Oxygen-Containing Heterocycles. Catalysts 2017, 7, 37. [CrossRef]

2. Wang, S.-Y.; Laborda, P.; Lu, A.-M.; Duan, X.-C.; Ma, H.-Y.; Liu, L.; Voglmeir, J. N-acetylglucosamine 2-Epimerase from Pedobacter heparinus: First Experimental Evidence of a Deprotonation/Reprotonation Mechanism. Catalysts 2016, 6, 212. [CrossRef]

3. Andrews, F.H.; Wechsler, C.; Rogers, M.P.; Meyer, D.; Tittmann, K.; McLeish, M.J. Mechanistic and Structural Insight to an Evolved Benzoylformate Decarboxylase with Enhanced Pyruvate Decarboxylase Activity. Catalysts 2016, 6, 190. [CrossRef]

4. Wang, X.; Yang, L.; Cao, W.; Ying, H.; Chen, K.; Ouyang, P. Efficient Production of Enantiopure D-Lysine from L-Lysine by a Two-Enzyme Cascade System. Catalysts 2016, 6, 168. [CrossRef]

5. Rivero, C.W.; Palomo, J.M. Covalent Immobilization of Candida rugosa Lipase at Alkaline $\mathrm{pH}$ and Their Application in the Regioselective Deprotection of Per-O-acetylated Thymidine. Catalysts 2016, 6, 115. [CrossRef]

6. Alnoch, R.C.; Rodrigues de Melo, R.; Palomo, J.M.; Maltempi de Souza, E.; Krieger, N.; Mateo, C. New Tailor-Made Alkyl-Aldehyde Bifunctional Supports for Lipase Immobilization. Catalysts 2016, 6, 191. [CrossRef]

7. Herrero, C.; Nguyen-Thi, N.; Hammerer, F.; Banse, F.; Gagné, D.; Doucet, N.; Mahy, J.-P.; Ricoux, R. Photoassisted Oxidation of Sulfides Catalyzed by Artificial Metalloenzymes Using Water as an Oxygen Source. Catalysts 2016, 6, 202. [CrossRef]

8. Scholtissek, A.; Tischler, D.; Westphal, A.H.; van Berkel, W.J.H.; Paul, C.E. Old Yellow Enzyme-Catalysed Asymmetric Hydrogenation: Linking Family Roots with Improved Catalysis. Catalysts 2017, 7, 130. [CrossRef]

9. Wang, Y.; Zhao, H. Tandem Reactions Combining Biocatalysts and Chemical Catalysts for Asymmetric Synthesis. Catalysts 2016, 6, 194. [CrossRef]

(C) 2018 by the authors. Licensee MDPI, Basel, Switzerland. This article is an open access article distributed under the terms and conditions of the Creative Commons Attribution (CC BY) license (http:/ / creativecommons.org/licenses/by/4.0/). 